\title{
CARACTERIZAÇÃO DOS MEIOS E MÉTODOS DE INFLUÊNCIA PRÁTICA NO TREINAMENTO EM FUTEBOLISTAS PROFISSIONAIS
}

\author{
MS. TIAGO VOLPI BRAZ \\ Mestre em Educação Física pela UNIMEP e Professor do Depto. de Educação Física da Faculdade de \\ Americana (Poços de Caldas - Minas Gerais - Brasil) \\ E-mail: tiagovolpi@yahoo.com.br
}

\author{
MS. LEANDRO MATEUS PAGOTO SPIGOLON \\ Mestre em Educação Física pela UNIMEP e Equipe de Fisiologia do Desportivo Brasil Participações \\ LTDA. (Piracicaba - São Paulo - Brasil) \\ E-mail: leandro_edfisica@hotmail.com

\section{DR. JOÃO PAULO BORIN} \\ Doutor em Educação Física pela UNICAMP e Professor do Depto. de Ciências do Esporte da \\ Universidade Estadual de Campinas (Campinas - São Paulo - Brasil) \\ E-mail: borinjp@fef.unicamp.br
}

\begin{abstract}
RESUMO
O presente trabalho tem como objetivo apontar as características dos meios e métodos de influência prática e, posteriormente, sugerir um modelo de organização e estruturação na etapa preparatória, na modalidade futebol profissional. Os instrumentos utilizados na pesquisa foram artigos publicados em periódicos indexados no Qualis CAPES, dissertações, bem como livros registrados no International Standard Book Number (ISSN). A partir das informações encontradas, destaca-se que o meio de treinamento representa o exercício, e o método o modo de sua utilização; os métodos de influência prática têm sido tratados com maior importância no âmbito desportivo. A discussão direciona no sentido de que os diferentes meios e métodos constituem os elementos práticos da preparação desportiva, intenvindo diretamente na organização do treinamento, bem como no entendimento de que quanto maior é o grau de correspondência entre os modelos utilizados (exercícios de treinamento) e a competição, maiores e mais eficazes resultarão seus efeitos. Por fim, aponta-se que no contexto atual da modalidade, torna-se necessário evidenciar que a forma de organização deve buscar o desempenho dos jogadores em curto período de tempo, e a preparação de futebolistas profissionais indica a necessidade de pesquisas envolvendo propostas de sistematização de treinamento.
\end{abstract}

PALAVRAS-CHAVE: Meios de treinamento; métodos de treinamento; futebol; treinamento esportivo. 
A melhoria do desempenho dos desportistas depende, em grande parte, da habilidade das comissões técnicas em selecionar e organizar os conteúdos de treinamento relacionados à prática competitiva de uma determinada modalidade desportiva. De acordo com Gomes (2009), a base metodológica da preparação desportiva' é constituída por meios e métodos pedagógicos de preparação que visam aperfeiçoar as capacidades de desempenho até um estado ótimo, mantendo sempre o equilíbrio entre os sistemas biológico, psicológico e social.

Os meios de treinamento influenciam direta e/ou indiretamente o aperfeiçoamento para alcançar o alto desempenho desportivo, constituindo a base do processo pedagógico da preparação (PLATONOV, 2008). Podem ser consideradas um sistema estável de ações repetidas, com interligações necessárias para a solução de tarefas previstas, e obrigatoriamente estão ligados aos métodos da preparação desportiva (GOMES, 2009). Já os métodos da preparação desportiva compreendem a forma como os treinadores e atletas utilizam as ferramentas no treinamento, visando alcançar a assimilação dos conhecimentos, habilidades e hábitos. São procedimentos planejados na transmissão e estruturação de conteúdos de treinamento (MARTIN; CARL; LEHNERTZ, 2008), ou seja, é como se utiliza o meio no processo de obtenção do objetivo da preparação. Sucintamente, o meio representa o exercício, e o método, o modo de sua utilização (DE LA ROSA, 2006).

Neste sentido, importante destacar que, para cada componente do sistema de preparação do atleta, existe uma composição de métodos. Assim, o ato de verbalizar, demonstrar ou praticar são critérios utilizados para classificar os métodos pedagógicos do desporto em i) métodos de influência prática, ii) de influência verbal (explicação, conversa, comando, correção e avaliação) e iii) influência demonstrativa (visual, motor, auditivo) (ZAKHAROV; GOMES, 2003). Os métodos de influência verbal e demonstrativos são complementares aos de influência prática, porém, são necessários ao processo de preparação, já que se atrelam ao binômio treinador-atleta, sobretudo em atividades que visem à apresentação da atividade motora, demonstração de materiais didáticos, orientações visuais e estímulos sonoros (GOMES, 2009).

Ao mesmo tempo em que se verifica contextualizado na literatura (WEINECK, 2003; PLATONOV, 2008), os conceitos relacionados aos meios e métodos

I. A preparação desportiva compreende todos os fatores relacionados com a preparação do atleta e que podem levá-lo ao desenvolvimento de uma boa performance no desporto praticado. É composta pelo sistema de competições, sistema de treinamento e sistema de fatores complementares (GOMES, 2009). 
da preparação desportiva, Thiess, Tschiene e Nickel (2004) entendem que sua caracterização de maneira específica das modalidades desportivas tem sido pouco explorada na literatura, o que contribui para aplicação sem especificidade dos exercícios de treinamento (REILLY, 2005), dificultando o aperfeiçoamento das capacidades de desempenho dos atletas durante o processo de preparação desportiva. Além disto, nos desportos individuais essa área caminhou com maior propriedade, até mesmo pelo menor envolvimento de variáveis a serem consideradas para obter o resultado de modo mais objetivo, e pela forma como é avaliado o desempenho; porém, nos desportos coletivos, as tentativas e propostas ainda se encontram no campo exploratório, e os estudos ainda são escassos (BORIN; GOMES; LEITE, 2007; BORIN et al., 2009; BRAZ, 20I0; SPIGOLON, 20I0) em diversas modalidades.

Particularmente quanto ao futebol, apesar de se destacar no cenário desportivo brasileiro, poucos estudos procuraram caracterizar os meios e métodos de preparação na organização e estruturação de futebolistas (sub 20) e profissionais da modalidade, em exceção, as descrições realizadas por Gomes e Souza (2008) para uma equipe da série A do campeonato brasileiro. Tal ocorrência se deve, provavelmente, em consequência dos principais clubes nacionais não disponibilizarem sua estrutura organizativa de trabalho, ou pela distância existente entre a sistematização do rigor científico e a realidade empírica da modalidade (BRAZ, 20 I0).

A estruturação dos meios e métodos de treinamento durante a temporada competitiva deve ser tal que permita, ao futebolista, desempenho constante durante longo período competitivo, ou seja, oito a nove meses no ano (GAMBLE, 2006; KELLY; COUTTS, 2007), somado ao pouco tempo de preparação das equipes devido ao calendário de competições. Nesta direção, surge a necessidade da especialização dos exercícios de aperfeiçoamento das capacidades de desempenho, apontando para uma relação da realidade competitiva e as características do treinamento (MATVEEV, 200 I ; THIESS; TSCHIENE; NICKEL, 2004; PLATONOV, 2008; CASTELO, 2009), o que, certamente, exige pesquisas caracterizando exercícios de preparação.

Assim, constata-se a necessidade de estudos que busquem a caracterização dos meios e métodos de influência prática na estruturação dos modelos de treinamento para futebolistas, buscando, também, demonstrar com exemplos práticos a maneira como são selecionados e organizados durante o processo de preparação, tendo em vista a condição de prescrição do treinamento baseado na modelação competitiva da modalidade. Diante deste contexto, o presente trabalho busca apontar as características dos meios e métodos de influência prática e, posteriormente, relacionar com a estrutura e organização do treinamento no futebol. 
presente estudo trata-se de uma síntese de pesquisa, não sendo apenas um resumo da literatura a que se refere, mas sim, um tipo lógico de pesquisa, que resulta em conclusões válidas, avaliações de uma hipótese, revisão e proposta de teoria (THOMAS; NELSON, SILVERMAN, 2007).

Os instrumentos utilizados foram artigos publicados em periódicos indexados da Coordenação de Aperfeiçoamento de Pessoal de Nível Superior (Qualis CAPES), dissertações e livros registrados no International Standard Book Number (ISSN). Os artigos foram obtidos no Portal CAPES por meio das bases de dados EBSCO HOST, SCOPUS, além da Scientific Electronic Library Online (SCIELO), sendo selecionados conforme mensuração dos desfechos de interesse (SAMPAIO; MANCINI, 2007) necessários para atender os objetivos propostos no estudo.

Os critérios de seleção de livros foram: i) Publicação a partir do ano 2000, ii) pertencer à área do Treinamento Desportivo, iii) constar na descrição a temática "exercícios, meios e métodos de preparação desportiva" ou "exercícios de treinamento para futebolistas" e iv) estar em idioma português. Quanto à escolha das dissertações, definiu-se como palavra-chave: futebol, exercícios de treinamento, meios e métodos de treinamento.

\section{RESULTADOS}

A partir da metodologia proposta, a Tabela I aponta os dados obtidos.

Tabela I - Unidades observacionais segundo variáveis estudadas

\begin{tabular}{c|c|c|c|c}
\hline & Artigos Publicados & Dissertações & Livros & Total \\
\hline Unidade Observacional $(\mathrm{n})$ & 12 & 3 & 15 & 30 \\
\hline
\end{tabular}

\section{DISCUSSÃO}

\section{OS MÉTODOS DE INFLUÊNCIA PRÁTICA}

Os métodos de influência prática têm sido tratados com maior importância no âmbito desportivo, já que constituem os elementos práticos da preparação desportiva, intervindo diretamente na organização do treinamento (GOMES; SOUZA, 2008; GOMES, 2009). De fato, esta intervenção direta no treinamento corresponde 
às práticas sistematizadas voltadas, principalmente, para melhoria dos componentes técnico, físico e tático dos desportistas, bem como intervenções direcionadas à recuperação dos atletas durante a sequência de sessões de treinos e jogos.

Particularmente quanto aos métodos de ensino da técnica, Platonov (2008) relata dois principais enfoques metodológicos: a) integral e b) parcial. $\bigcirc$ primeiro pressupõe o estudo e desenvolvimento das ações técnicas (fundamentos) de uma vez, ou seja, com caráter global. Em contrapartida, o parcial ou analítico-sintético, representa a divisão das ações em elementos ou fases relativamente independentes, cuja aprendizagem é realizada de modo autônomo, com a posterior ligação destes em algo único (ZAKHAROV; GOMES, 2003). Ao mesmo tempo em que há possibilidade de maior concentração na fase destacada dos meios executados, com o aperfeiçoamento detalhado por meio das correções imediatas do treinador, permite-se de maneira integral o aumento da complexidade da ação motora, estabilidade do ritmo e sua estrutura geral, consolidando a aprendizagem (MATVEEV, 1997).

Para os métodos do componente físico, atenção especial deve ser direcionada à capacidade biomotora a ser desenvolvida ou aperfeiçoada, considerando não somente o tipo de ação muscular, mas também a estrutura do movimento, volume e intensidade da carga e, sobretudo, da relação com a atividade competitiva do desportista (TUBINO, MOREIRA, 2003; WEINECK, 2003; BOMPA, 2005; BARBANTI, 20 I0). Para a capacidade e potência aeróbia destacam-se os métodos contínuos, realizados sem pausas intermediárias de recuperação, e apresentam duas formas de execução: permanente e variativo (GOMES et al., 1997). Normalmente, os métodos de características permanentes são empregados em meios de treino peculiares à recuperação dos desportistas, com exceção de algumas modalidades, que se modelam por parâmetros longos e constantes das cargas competitivas. Outra opção seriam os métodos intervalados ou fracionados, que são norteados por meios que geram trocas sistemáticas entre o esforço a realizar e a pausa relativa de recuperação, constituindo métodos de maior exigência funcional (DE LA ROSA, 2006).

Para a resistência, Weineck (2003) classifica os métodos no desenvolvimento e aperfeiçoamento desta capacidade pelo volume e intensidade da carga, em extensivo (alto volume de trabalho) e intensivo (maior intensidade de trabalho), e os de velocidade pelo seu desenvolvimento complexo com elementos técnicos e táticos, ou, ainda, pela sua intensidade, máxima e submáxima.

Para os métodos de força, Tubino e Moreira (2003) e Platonov (2008) vinculam os tipos de ação muscular durante a execução do meio, sendo divididos em métodos concêntricos, excêntricos, isométricos, pliométricos, isocinéticos e de resistência variável. 
Por fim, a flexibilidade pode ser treinada tanto pelo método passivo, como pelo ativo ou combinado, com aplicabilidade de cargas adicionais, ou com a ajuda de um companheiro (BOMPA, 2005).

Outro ponto relevante volta-se aos métodos competitivos e de jogos, pois, apesar de se caracterizarem pelo difícil controle da carga, imprevisibilidade das ações motoras e pela dificuldade de direcionamento do atleta no processo de execução dos meios (MATVEEV, 200 I; DE LA ROSA, 2006; MARTIN; CARL; LEHNERTZ, 2008), tem sido amplamente valorizados na preparação dos jovens desportistas (ZAKHAROV; GOMES, 2003), pois definem diversas tarefas de preparação dos atletas, e sua eficiência resulta no aperfeiçoamento desportivo, porém, fatores como o baixo condicionamento físico e nível inicial da aprendizagem da técnica limitam sua utilização (PLATONOV, 2008).

Destaca-se, ainda, que os métodos competitivos e de jogo também podem ser utilizados para o desenvolvimento do componente tático em desportos coletivos, já que são condicionados pela especificidade da modalidade, ilustrados pelas múltiplas repetições de meios de preparação especial e competitivos, como o controle da velocidade e tempo percorrido, caráter e magnitude do esforço desenvolvido, caracterizando-se, de acordo com Platonov (2008), por meios que utilizam o confronto com o adversário, atuação de um companheiro e fragmentos de situações competitivas.

Nota-se ainda que, além dos métodos de desenvolvimento das capacidades técnica, física (motora) e tática, existem os métodos de recuperação, que objetivam, sobretudo, aperfeiçoar o processo de compensação das cargas de treinamento. Platonov (2008) os classifica como métodos pedagógicos, psicológicos e biomédicos que, de maneira geral, utilizam meios farmacológicos, físicos, psíquicos, higiênicos e alimentícios na sua forma de aplicação. Meios alimentícios são comprovadamente determinantes para a preparação desportiva, em especial, a reposição de líquidos e a ingestão de carboidratos durante os treinamentos e competição (WEINECK, 2003). Tais abordagens previnem a deterioração do desempenho, e atuam na recuperação do organismo do desportista (BOMPA, 2005). Sob essa perspectiva, Platonov (2008) afirma que a rentabilidade desportiva está diretamente ligada à aplicação dos meios e métodos de recuperação e estimulação do desempenho durante as diversas etapas do treinamento.

A Tabela 2 apresenta os diferentes métodos e meios de influência prática nos diferentes componentes do treinamento, que podem ser utilizados no treinamento do futebol. 
Tabela 2 - Métodos e meios de influência prática segundo componentes do Treinamento Desportivo

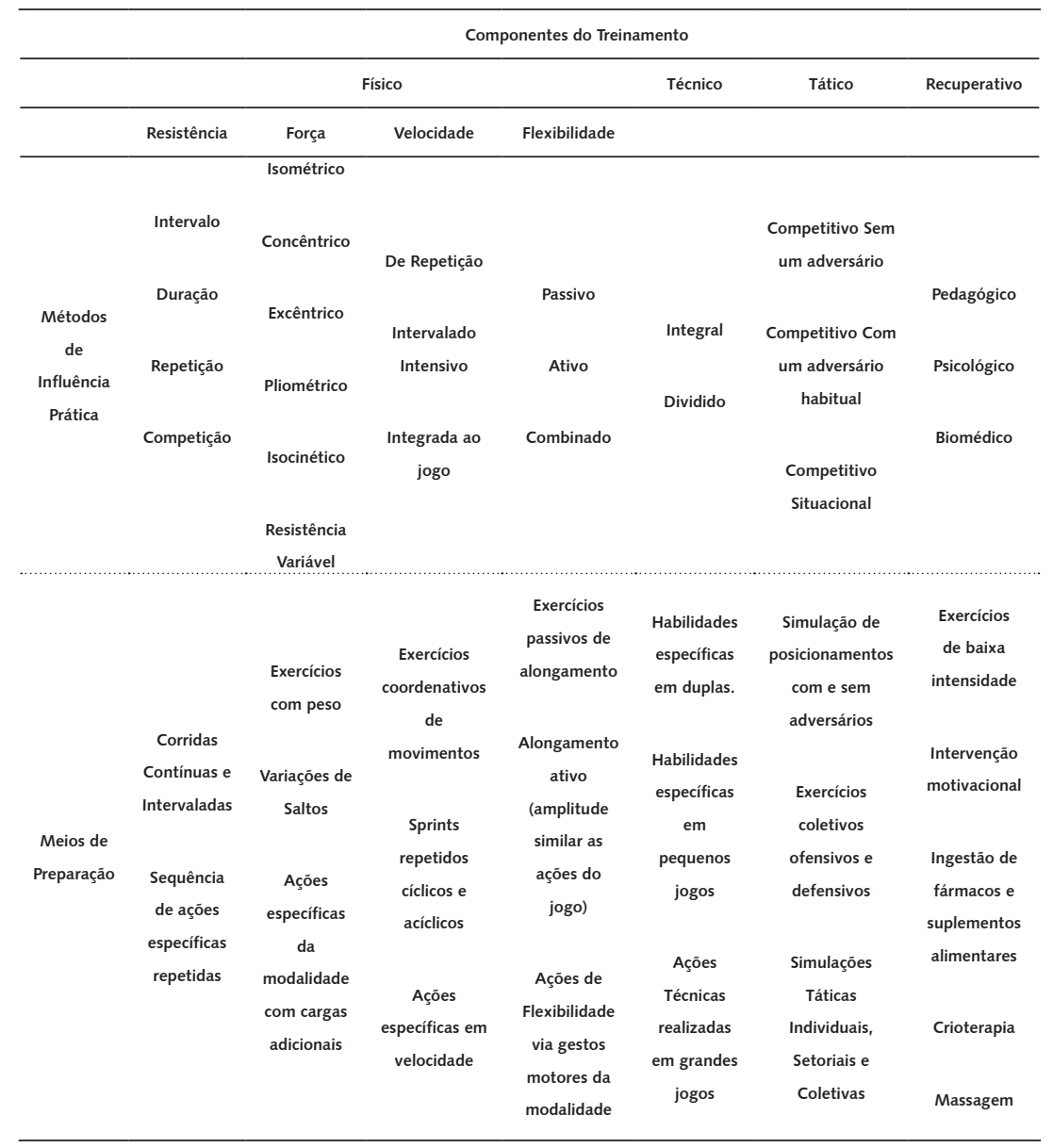

Cabe destacar que, no processo de preparação dos futebolistas, existem diversas possibilidades de aplicação dos meios e métodos de influência prática. Em Gomes e Souza (2008) e Spigolon (2010), são descritos exercícios e formas de trabalhos utilizados para futebolistas, dos quais se destacam: corridas intervaladas, corridas com variação de velocidade e direção, corridas tracionadas em distâncias curtas, corridas em aclive (rampa), exercícios coordenativos de corrida e habilidades específicas, saltos verticais, horizontais, laterais, pliométricos, exercícios com pesos, alongamentos dinâmicos, exercícios com variações técnicas (finalização, passe, do- 
mínio, condução e drible), simulações de jogo e situações táticas específicas, bem como jogos em campo reduzido.

No entanto, é necessário enfatizar que a aplicação destes exercícios e sua forma de trabalho devem priorizar a especificidade competitiva da modalidade, sobretudo a partir da categoria sub 20 ( 8 a 20 anos). Esta especificidade tem sido relacionada ao princípio da modelação competitiva, processo no qual se busca a correlação entre o exercício de preparação com a exigência específica da competição (MATVEEV, 200 I ; PLATONOV, 2008). Segundo este pensamento, quanto maior é o grau de correspondência entre os modelos utilizados (exercícios de treinamento) e a competição inerente ao jogo de futebol, maiores e mais eficazes resultarão seus efeitos, fundamentando-se, desta forma, a otimização do processo de preparação (THIESS; TSCHIENE; NICKEL, 2004). A conceituação de exercícios de preparação específica passa pela construção de modelos, parciais ou integrais, que buscam representar fielmente a realidade competitiva do jogo de futebol (CASTELO, 2009). Estes modelos são constituídos de indicadores, como número de passes, saltos, tipos de deslocamentos executados, distância total percorrida nos diferentes períodos de jogo e intensidades, tempo de permanência no ataque e defesa, eficiência das ações (BORIN; GOMES; LEITE, 2007), biomecânica de habilidades técnicas, bem como variáveis relacionadas à forma de atuar das equipes, como táticas, estratégias e sistema de jogo adotados pelos treinadores.

Assim, a partir da modelação competitiva dos jogadores e equipes, são exemplos de meios de treinamento especiais e competitivos para o futebol: sprints cíclicos e acíclicos em distâncias de cinco a 30 metros; estações com variações de saltos, mudanças de direção e deslocamentos; corridas intervaladas ( > 85\% $\left.\mathrm{VO}_{2 \text { máx }}\right)$ com pausas e movimentações baseadas no volume de ações competitivas; exercícios com pesos, dinâmicos com estrutura, velocidade e amplitude similar aos gestos competitivos da modalidade; exercícios com variações técnicas; jogos em campo reduzido com alta intensidade; simulações ofensivas e defensivas do padrão de atuação da equipe, buscando particularidades individuais dos futebolistas no processo coletivo do jogo.

\section{ESTRUTURAÇÃO DOS MEIOS E MÉTODOS DE INFLUÊNCIA PRÁTICA NA PREPARAÇÃO DE FUTEBOLISTAS}

A partir da caracterização dos meios e métodos de influência prática na preparação de futebolistas, surge a necessidade de periodizá-los ao longo da temporada competitiva. Acerca desta temática, parece importante atentar-se para alguns pontos que o contexto prático da modalidade apresenta, sobretudo em relação ao pouco tempo de preparação destinado à preparação dos jogadores, alto volume compe- 
titivo durante a temporada e necessidade de desempenho durante longo período de tempo (ISSURIN, 20 I0; MOREIRA, 20 I0). Além disto, torna-se imprescindível a adoção de estruturações que considerem a relação dos efeitos crônicos e agudos das capacidades determinantes (potência muscular, velocidade e agilidade) e predominantes (manifestações da resistência), com a especificidade dos meios e métodos de preparação da modalidade (BRAZ, 20 I 0; SPIGOLON, 20 I0). De fato, Gomes e Souza (2008) relatam que a maioria das equipes profissionais brasileiras apresentam período de 4 a 6 semanas, no início da temporada, para se prepararem para todos os jogos a serem disputados durante o ano. Neste contexto, torna-se necessário evidenciar modelos de organização que busquem o desempenho do futebolista em curto período de tempo, já que após o primeiro mesociclo de preparação, já serão disputadas partidas oficiais.

A partir do entendimento de que a competição é a manifestação máxima da performance de um desportista (PLATONOV, 2008), e que a própria atividade competitiva dos futebolistas atua como estímulo específico para o desenvolvimento do desempenho na modalidade (BRAZ, 20 I0), nota-se que o volume competitivo de equipes de futebol profissional é elevado (ISSURIN, 20I0).

Considerando a problemática do tempo reduzido de preparação das equipes, e a necessidade de desenvolvimento das capacidades biomotoras, com predomínio dos sistemas neural e muscular (potência, velocidade e agilidade), sugere-se que os métodos de treinamento (intervalados ou contínuos em baixa intensidade) realizados sem a presença da bola, não seriam necessários para o desenvolvimento da resistência dos futebolistas, já que os próprios treinamentos com bola atuariam neste sentido, como sugerido por Hoff e Helgerud (2004) e confirmado pelos achados de Impellizzeri et al. (2006). Indica-se que os estímulos da atividade competitiva e treinamentos com bola voltados à resistência especial dos futebolistas, sejam utilizados para melhoria da capacidade de resistência especial dos jogadores, diminuindo o volume de treino por meio de corridas intervaladas (potência aeróbia), contínuas, longa duração e baixa intensidade (resistência aeróbia).

Além disto, há a possibilidade dos treinadores enfatizarem o componente tático da preparação no desenvolvimento dos sistemas de jogo, como adequação às características dos jogadores entre outras atividades, pois, normalmente, após 5 a 6 semanas, já ocorre a primeira partida oficial do campeonato.

Portanto, no início e decorrer da temporada, o volume de preparação tática, bem como os jogos, atuariam na manutenção da resistência especial dos jogadores. Tal entendimento levaria à possibilidade de elevação do volume de treinamento das capacidades neuromusculares dos futebolistas no início da temporada, sobretudo, 
quanto ao treinamento da velocidade cíclica e acíclica, bem como a potência muscular, consideradas imprescindíveis para a modalidade.

Por exemplo, uma equipe que destina seis semanas para a etapa preparatória: o primeiro microciclo (normalmente de controle, associado com testes e avaliações) atuaria como fator de preparação inicial dos futuros estímulos neuromusculares, que seriam aplicados na segunda semana de preparação. Nos próximos microciclos, em que, durante os sete dias de treinamento, normalmente são prescritas de 9 a 12 sessões de treinamento, sugere-se a seguinte estrutura: 3 a 6 sessões de treinamentos das capacidades neuromusculares e 6 a 9 sessões de treinamentos voltadas à resistência especial, destacadamente, com utilização de trabalhos com bola para realização de ações técnicas em pequenos e grandes jogos; exercícios táticos coletivos ofensivos e defensivos; simulação de posicionamentos com e sem adversários, entre outros.

Ponto a ser valorizado volta-se ao princípio da especificidade, pois devido ao reduzido tempo de preparação, os meios de treinamentos com componentes gerais não possuem relação com o desempenho dos jogadores, sobretudo, na categoria profissional da modalidade. Entretanto, para que o treino de resistência especial tenha um efeito real em todos os exercícios e em todas as repetições, os atletas devem garantir uma velocidade de execução semelhante à solicitada na competição (BARBANTI, 20 I0). Tal premissa deve ser norteadora na prescrição de treinamentos coletivos e em campo reduzidos (IMPELLIZZERI et al., 2006), mesmo quando especificados jovens futebolistas, especialmente na categoria sub 20.

Neste sentido, torna-se importante atentar para a intensidade deste tipo de treinamento, evitando volumes elevados de trabalho, tanto em termos de minutos de execução, quanto em quantidade de exercícios. Para o desenvolvimento das manifestações neuromusculares no futebol, sugere-se priorizar a intensidade das ações executadas, elaborando meios que exijam níveis de concentração elevados por parte dos jogadores, decisões rápidas, movimentos eficazes em pequeno espaço e curto período de tempo, sobretudo, ocasionando adaptações relacionadas ao metabolismo anaeróbio lático e alático. Como exemplo para melhoria do componente neuromuscular dos futebolistas, os treinamentos realizados com bola (especialmente treinamentos coletivos e em campos reduzidos) devem ser executados em alta intensidade, com prioridade para deslocamentos acima de $19 \mathrm{~km} / \mathrm{h}$, diminuindo o volume de corridas de baixa intensidade $(<$ I I km/h), já que elevado volume destas ações poderão implicar em efeitos negativos nas capacidades neuromusculares de treinamento (GAMBLE, 2006; ISSURIN, 20 I0).

Nesta perspectiva, o quadro I apresenta uma sugestão de mesociclo de preparação para futebolistas profissionais, contendo a relação dos meios e méto- 
dos de treinamento, as capacidades de desempenho e a sequência de aplicação durante as semanas. A distribuição do volume e intensidade dos diferentes meios e métodos de treinamento sugeridos, busca a manutenção do volume de trabalho e variabilidade da intensidade adotada nos meios de preparação, priorizando o treinamento das capacidades neuromusculares como potência muscular, velocidade cíclica e acíclica na maioria dos mesociclos da temporada competitiva. De fato, ao observar os apontamentos de Issurin (20 I 0), no contexto da temporada anual em modalidades coletivas (8 meses de competição), conceitos generalizados de pico de desempenho e tapering não se justificam, já que o desempenho deve ser constante durante todos os jogos, sobretudo em competições não eliminatórias. Tal fato corrobora com Moreira (20 I 0), que aponta para a necessidade da estruturação de treinamento, na modalidade futebol, por meio de uma abordagem particular com perspectivas diferentes e específicas, que extrapolam o modelo de periodização tradicional do treinamento. 


\begin{tabular}{|c|c|c|c|c|c|c|c|c|c|c|c|}
\hline & 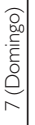 & 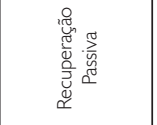 & 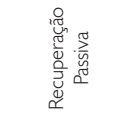 & & 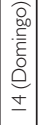 & 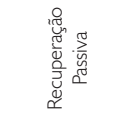 & 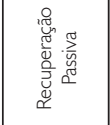 & & 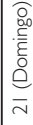 & 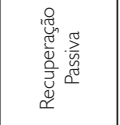 & 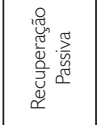 \\
\hline & 童 & 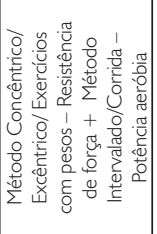 & 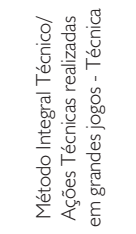 & & 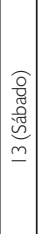 & 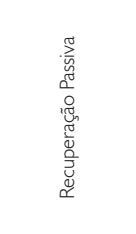 & 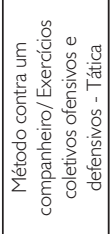 & & 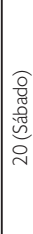 & 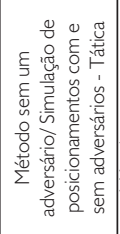 & 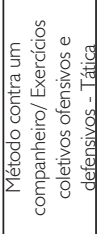 \\
\hline & 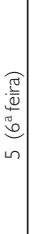 & 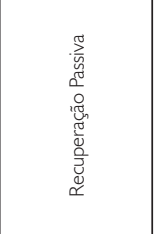 & 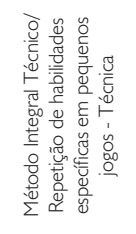 & & 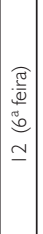 & 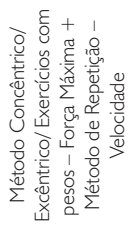 & 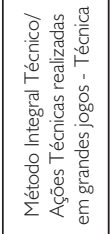 & & 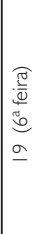 & 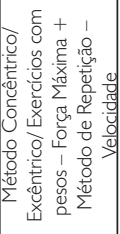 & 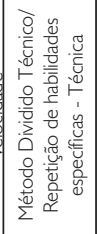 \\
\hline 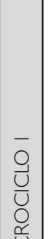 & 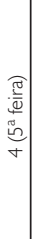 & 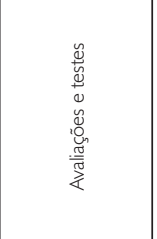 & 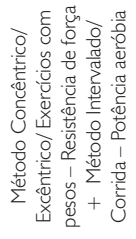 & 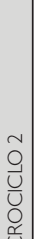 & 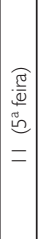 & 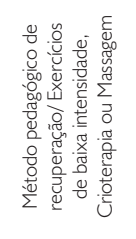 & 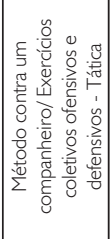 & 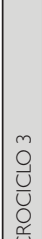 & 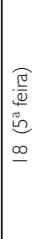 & 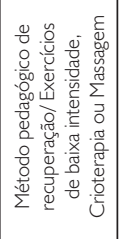 & 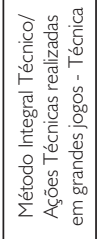 \\
\hline$\Sigma$ & 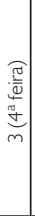 & 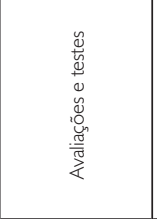 & 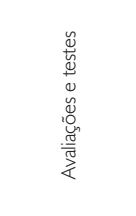 & $\Sigma$ & 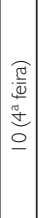 & 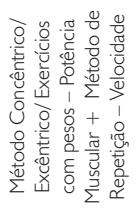 & 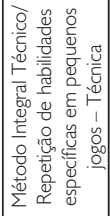 & ${ }^{\bar{\Sigma}}$ & 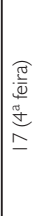 & 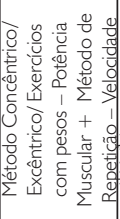 & 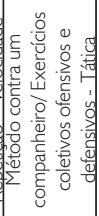 \\
\hline & 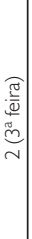 & 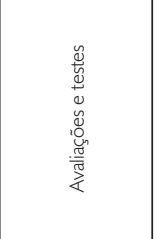 & 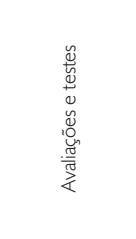 & & 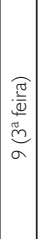 & 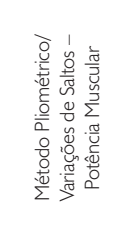 & 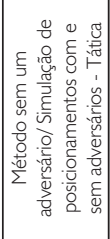 & & 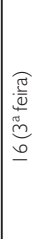 & 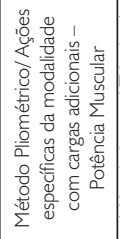 & 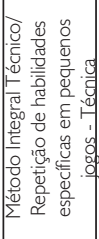 \\
\hline & 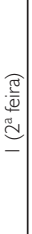 & 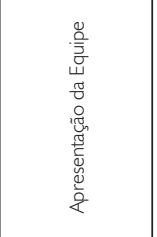 & 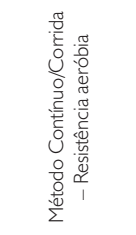 & & 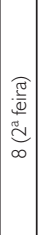 & 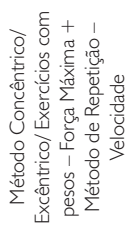 & 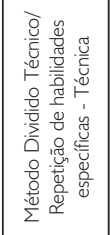 & & 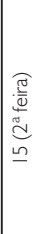 & 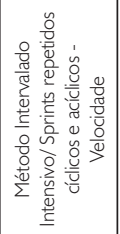 & 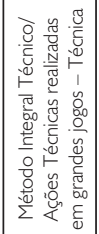 \\
\hline & 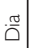 & $\Sigma$ & $\vdash$ & & 苋 & $\Sigma$ & $\vdash$ & & 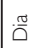 & $\Sigma$ & $\vdash$ \\
\hline
\end{tabular}




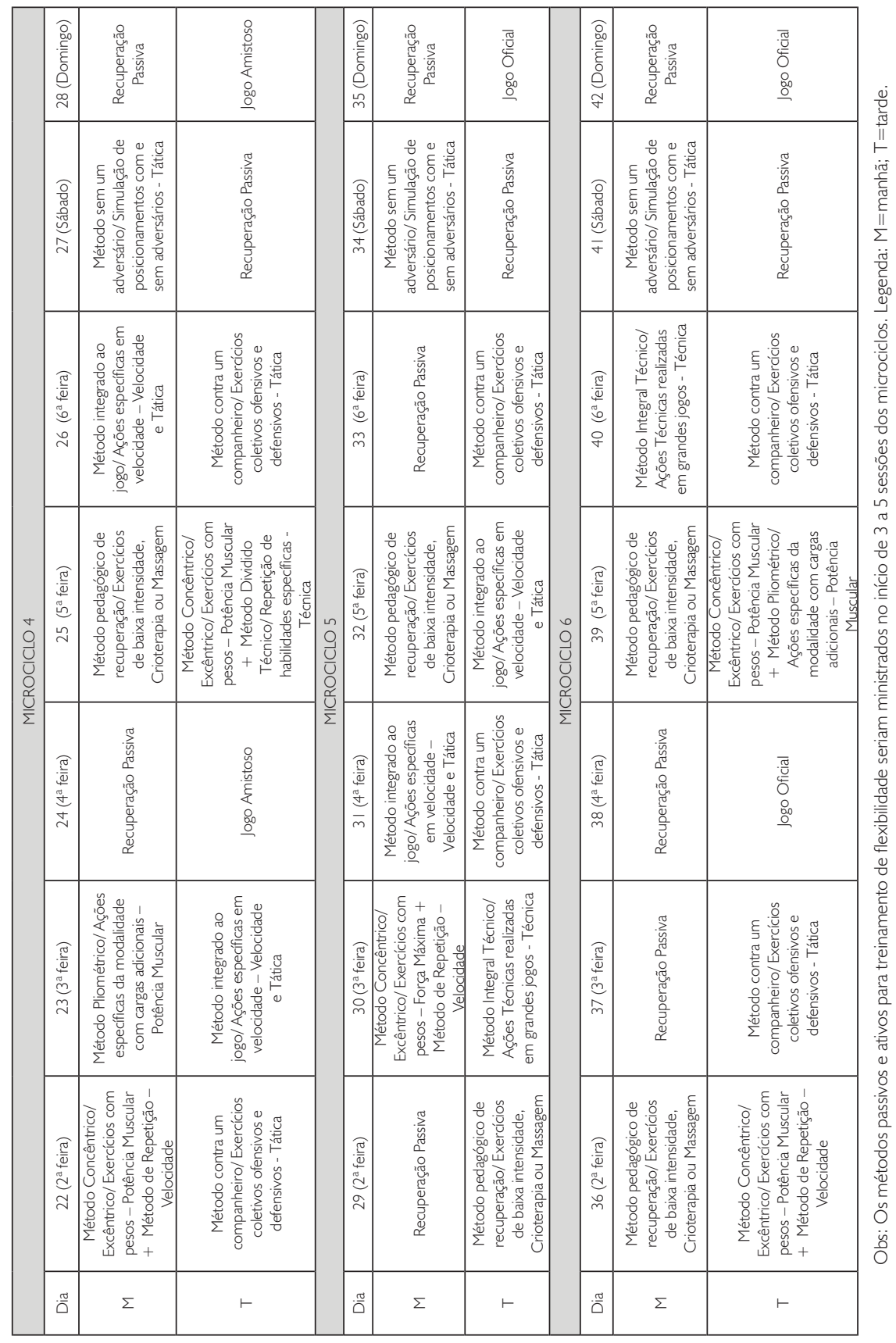




\section{CONSIDERAÇÕES FINAIS}

A partir do entendimento da necessidade de estruturação de treinamento na modalidade futebol, devido ao calendário competitivo, o presente estudo procurou contribuir com subsídios na organização e estruturação de meios e métodos de preparação para futebolistas. Cabe destacar, neste contexto, que é essencial em próximos trabalhos, a discussão e orientação quanto à carga de treinamento aplicada na sequência dos meios e métodos propostos, bem como sua forma de organização ao longo da temporada competitiva.

\section{Characterization of exercises and methods of practical influence in training of professional soccer players}

ABSTRACT: The purpose of this study was to point out the characteristics of exercises and methods, and then to suggest a structure model in the preparatory stage in professional soccer. The instruments used in the research were articles published in journals indexed in Qualis CAPES, dissertations, books registered in the International Standard Book Number (ISSN). We found out that the mean of training is the exercise and the method is how to use it; practical methods have been treated with the utmost importance in sports. The discussion guides in the sense that the different exercises and methods are the practical elements of sports preparation, directly intervening in the organization of training as well as on the understanding that the greater the degree of correspondence is between the models used (exercise training) and competition, larger and more effective result its effects. Finally it is noted that in the current context of the sport, it's necessary to show that the form of organization should seek the players' performance in a short period of time, and preparation of professional soccer indicates the need for proposals for research involving systematic training.

KEYWORDS: Exercises; methods; soccer; sport training.

\section{Caraterización de los ejercicios y métodos de influencia práctica en el entrenamiento de futbolistas profesionales}

RESUMEN: Este trabajo tiene como objetivo mostrar las características de los medios y métodos prácticos de preparación y proponer un modelo de organización en fútbol profesional. Los instrumentos utilizados fueron artículos publicados en revistas indexadas en Qualis CAPES, disertaciones, libros registrados en el International Standard Book Number (ISSN). La información que se encuentra indica que el meio de entrenamiento es lo ejercício y el método es la forma de su utilización; los métodos prácticos han sido tratados con la mayor importancia en los deportes. La discusión se dirige en el sentido de que los diferentes medios y métodos son los elementos prácticos para la preparación deportiva, interviniendo directamente 
en la organización de entrenamiento, así como en el entendimiento de que cuanto mayor sea el grado de correspondencia entre los modelos utilizados (ejercícios) y la competición, mayor sus resultados y más efectivos sus efectos. Finalmente, cabe señalar que en el actual contexto de este deporte, es necesario demostrar que la forma de organización debe buscar el rendimiento de los jugadores en un corto período de tiempo y para la preparación de los futbolistas profesionales indicase la necesidad de investigaciones que incluyen propuestas sistemáticas de entrenamiento.

PALABRAS-CLAVE: Ejercicios; métodos; fútbol; entrenamiento deportivo.

\section{REFERÊNCIAS}

BARBANTI, V. J. Treinamento esportivo: as capacidades motoras dos esportistas. Barueri: Manole, 2010.

BOMPA, T. O. Treinando atletas de desporto coletivo. São Paulo: Phorte, 2005.

BORIN, J. P.; GOMES, A. C.; LEITE, G. Preparação Desportiva: Aspectos do Controle da Carga de Treinamento nos Jogos Coletivos. Revista da Educação Física/UEM, Maringá, v. I 8 , p. 97-105, abril. 2007.

BORIN, J. P. et al. Alteração da capacidade de velocidade de deslocamento em futebolistas profissionais. Revista Motriz, Rio Claro, v. I5, p. 8, abr.jjun. 2009.

BRAZ, T. V. Alteração da velocidade em futebolistas juvenis no período competitivo e sua relação com o conteúdo de treinamento. 2010. 96 f. Dissertação (Mestrado em Educação Física) Faculdade de Ciências da Saúde, Universidade Metodista de Piracicaba, Piracicaba, 2010. Disponível em: https://www.unimep.br/phpg/bibdig/aluno/visualiza.php?cod=629. Acesso em: I 4 maio 2010.

CASTELO, J. Tratado general de fútbol: guía práctica de ejercicios de entrenamiento. Badalona: Paidotribo, 2009.

DE LA ROSA, A. F. Direções de treinamento: novas concepções metodológicas. São Paulo: Phorte, 2006.

GAMBLE, P. Periodization of training for team sports athletes. Strength and Conditioning Journal, Colorado Springs, v. 28, n. 5, p. 56-66,oct. 2006.

GOMES, A. C. Treinamento desportivo: estruturação e periodização. Porto Alegre: Artmed, 2002.

Treinamento desportivo: estruturação e periodização. 2. ed. Porto Alegre:

Artmed, 2009. 
GOMES, A. C. et al. Atletismo: treinamento individualizado para corredores de $10000 \mathrm{~m}$. Revista Treinamento Desportivo, Londrina, v. 2, n. 3, p. 59-64, 1997.

GOMES, A. C.; SOUZA, J. Futebol: treinamento desportivo de alto rendimento. São Paulo: Artmed, 2008.

IMPELLIZZERI, F. M. et al. Physiological and performance effects of generic versus specific aerobic training in soccer players. International Journal of Sports Medicine, New York, v. 27, p. 483-492, mar. 2006.

ISSURIN, V.B. New Horizons for the methodology and physiology of training periodization. Sports Medicine, Auckland, v. 40, n. 3, p. 189-206, mar. 2010.

HOFF, J.; HELGERUD, J. Endurance and strength training for soccer players: physiological considerations. Sports Medicine, Auckland, v. 34, p. 165-180, july 2004.

KELLY, V; COUTTS, A.J. Planning and monitoring training loads during the competition phase in team sports. Strength and Conditioning Journal, Colorado Springs, v. 29, n. 4, p. 32-37, aug. 2007.

MARTIN, D.; CARL, K.; LEHNERTZ, K. Manual de teoria do treinamento esportivo. São Paulo: Phorte Editora, 2008.

MATVEEV, L. P. Treino desportivo: metodologia e planejamento. Guarulhos: Phorte, 1997. Teoria general del entrenamiento deportivo. Barcelona: Paidotribo, 2001.

MOREIRA, A. La periodización del entrenamiento y las cuestiones emergentes: el caso de los deportes de equipo. Revista Andaluza de Medicina del Deporte, Sevilla, v. 3, n. 4, p. 170- |78, jul. 2010.

PLATONOV, V. N. Tratado geral de treinamento desportivo. São Paulo: Phorte 2008.

PLATONOV, V. N.; BULATOVA, M. M. La preparacion física. 4. ed. Barcelona: Paidotribo, 2001 .

REILLY, T. An ergonomics model of the soccer training process. Journal of Sports Science, London, v. 23, n. 6, p. 56I-572, june 2005.

SAMPAIO, R. F.; MANCINI, M. C. Estudos de revisão sistemática: um guia para síntese criteriosa da evidência científica. Revista Brasileira de Fisioterapia, São Carlos, v. I I , n. I , p. 83-89, jan./fev. 2007.

SOUZA, E. N. Alterações das capacidades biomotoras de jovens futebolistas durante macrociclo de treinamento: a partir da periodização de cargas seletivas. 2006. I 10 f. Dissertação (Mestrado em Educação Física) - Faculdade de Ciências da Saúde, Universidade Metodista de Piracicaba, Piracicaba, 2006. 
SPIGOLON, L.M.P. Diagnóstico e classificação dos conteúdos e volume do treinamento aplicado em futebolistas da categoria sub- 17 e sua relação da alteração das capacidades biomotoras em diferentes momentos do macrociclo. 20 10. 139 f. Dissertação (Mestrado em Educação Física) - Faculdade de Ciências da Saúde, Universidade Metodista de Piracicaba, Piracicaba, 20 I0. Disponível em: <http://www.unimep.br/phpg/bibdig/buscar.php?aut=0326540 I 08 |3\&ori=094923 |080.> . Acesso em: | 4 maio 2010.

STOLEN, T. et al. Physiology of soccer: an update. Sports Medicine, Auckland, v. 35, n. 6, p.50I-536, june 2005.

THIESS, G.; TSCHIENE, P.; NICKEL, H. Teoria y metodología de la competición deportiva. Barcelona: Paidotribo, 2004.

THOMAS, J. R.; NELSON, J. K.; SILVERMAN, S. J. Métodos de pesquisa em atividade física. 5. ed. Porto Alegre: Artmed, 2007.

TUBINO, M. J. G.; MOREIRA, S. B. Metodologia científica do treinamento desportivo. 13. ed. Rio de Janeiro: Shape, 2003.

WEINECK, J. Treinamento ideal. 9. ed. Barueri: Manole, 2003.

ZAKHAROV, A.; GOMES, A. C. Ciência do treinamento desportivo. Rio de Janeiro: Grupo Palestra Sport, 2003.

Recebido: 28 dez. 2008

Aprovado: 5 set. 2010

Endereço para correspondência:

Tiago Volpi Braz

Rua Cirilo Silva, 106

Bairro Funcionários

Poços de Caldas-MG

CEP: $37701-306$ 